\title{
Home Cultures and Idiom Processing: A Short Cut to Encyclopaedic Assumptions of Idioms
}

\begin{abstract}
Salim Bouherar, Mohamed El Bachir El Ibrahimi University, Algeria

URL:http://dx.doi.org/10.19044/esj.2020.v16n8p31

Abstract

This paper forms a part of my $\mathrm{PhD}$ research on idiom comprehension and processing through home cultures. The article argues that using home cultural assumptions in teaching idioms could result in easy and quick processing of such figurative aspects of speech. Shedding light on the nature of teaching, however, reveals that teaching English in Algeria is a fairly target culture-based process. This can slow the comprehension process and on some occasions, confuse the learner. This paper reveals the results of a set of semistructured interviews and comprehension tests that were conducted with teachers and learners. Learners were divided into two groups and taught throughout a four-week period using teaching materials that assumed home and target culture lessons of idioms, respectively. Students sat for a pre- and a post-test and were also interviewed after finishing the lessons. The results revealed that students recorded positive reactions toward home culture based teaching of idioms. Comprehension tests also reported a significant difference between the two groups' performance on idiom comprehension.
\end{abstract}

Keywords: Idiom processing, linguistic imperialism, meaning adjustment, home culture, target culture

\section{Introduction}

For decades, English idioms have been taught with reference to target cultures (British and American cultures, in particular) and this teaching practice is still pervasive nowadays. Many authors (e.g. Yagiz \& Izadpanah 2013, Rodriguez \& Winnberg 2013, Al-Sayyed \& Dweik 2015, Thyab 2016) avow the positive link of teaching target cultures and the easy-processing of idioms, notwithstanding that many of them focalised around the practical teaching aspects and not cognitive processing. What appears to be very polemic here is that the cognitive side is disregarded although it should be the first facet ever to be considered when discussing idioms' teaching approaches. I have pointed elsewhere, (Bouherar, 2017), that teaching idioms through 
target cultures can threaten the encyclopaedic assumptions raised by learners through an inferential route process and therefore, fail in arriving at the intended pragmatic meaning communicated by the speaker. Having said all that, however, how is it possible to teach idioms with reference to home cultures?

Ferraro and Andreatta (2014) discuss the Sapir-Whorf hypothesis, which is commonly thought to claim that language affects the way we act and perceive our surroundings and beliefs. It is this relationship between language, thought, and culture that is involved in how much language is affected by culture or vice versa. As a result of this, speaking one's first language in class means using his/her culture, explicitly or implicitly. The relevance theory principle of effect and effort supports this idea that the cognitive loads provided by target cultures can lead, very often, to a high cost of cognitive processing efforts and therefore slow the process of comprehension.

This paper aims to reveal the mechanisms of idiom processing and comprehension using home cultural contexts. Linguistic imperialism, as it is explained in this paper, dictates how English should be taught in countries where English is spoken as a second or a foreign language. This is a form of prescriptive English (criticised by Saussure who favoured the descriptive study of language) in the sense that there are guidelines on what to teach with reference to a British or an American educational context, which do not function at all in other countries. Not only does integrating home cultures to teaching idioms challenge the existing prescriptive norms of education but it also encourages the reform in teaching other aspects of language (i.e. grammar, written expression, speaking...etc.) by paying more attention to the cultural contexts of learners that can be more beneficial when used in class.

\section{Adjustment of language meaning}

Typical linguistic utterances ${ }^{1}$ apply the feature of broadening and narrowing of meaning. At the level of words, there are three types of concepts that each word has: there is the lexical concept, the logical and the encyclopaedic concept (Clark, 2013). The lexical level of a word gives information about the nature of the word, the class and the pronunciation, the logical level shares information about the concept that individuals have in mind when using the word and the encyclopaedic level gives rise to the individuals' experience about the word (Clark, 2013). For instance, (1) cloth (2) chair are two different words with different informational content. For (1) the lexical entry is that this word is a noun and its pronunciation is $/ \mathrm{klp} \theta /$ the logical entry of the word is that it is a property of a textile or fabric and it could be made of silk or wool, or cotton, it can take the shape of many clothes. The

\footnotetext{
${ }^{1}$ By typical linguistic utterances, I mean inferential.
} 
encyclopaedic entry: one of my friends bought a cloth from a nearby shop. Example (2), chair is a noun and is pronounced $/ \mathrm{t} \int \varepsilon: /$, this is the lexical entry. The logical entry: an object, a property of a house, a restaurant, a chair is also made of wood, steel. The encyclopaedic entry: last time I painted my chair in blue. Clark (2013) argues that the lexical and the logical entries of the word are shared by people who speak the same language but the encyclopaedic entry is differently thought of by individuals. However, these concepts are subjected to change from one culture to another. For instance, (3) religion is thought of similarly on a lexical and logical entry-level, even if individuals speak different languages. The same word would bring different encyclopaedic entries in different regions, an Iranian Muslim and a Saudi Muslim would think of Islam differently according to their practices and religious belongings. Sometimes, there are similar encyclopaedic entries between individuals when they share similar cultural backgrounds.

The comprehension of words does not happen without a modification (Clark, 2013) at the encyclopaedic entry level of the word. For example, (4) my computer's battery is flat has more than one meaning. Hearers of (4) have to adjust the meaning of 'flat' to understand what is meant by (4). The speaker does not mean that the battery is levelled but instead means there is a very low energy level and the device should be plugged into a charger.

The adjustment of idioms is somewhat different as idioms are attributed to the context they are used in. The comprehension of idioms through adjustment is complicated. For instance, (5) he kicked the bucket after being ill for months. The encyclopaedic property of 'ill' is made accessible by 'kick the bucket' as this meaning could be adjusted in the context to guarantee the expected implication (Vega Moreno, 2007). Some positive adjustment is linked to a different inferential and cognitive effect (Vega Moreno, 2007). That is, for hearers to think of illness and at the same time link it to kick the bucket, they have to draw a different inferential route with a different cognitive effect, too. In the case of (5), the inferential route is 'being ill for months' which also creates a different cognitive effect of death linked directly to 'kick the bucket' and strengthened by the actual context. These ideas are congruent with relevance theory arguments of how figures of speech are understood. However, relevance theory did not provide an adequate explanation of how the adjustment is made through an intercultural understanding of idioms. How learners can adjust the meaning of idioms through cultural assumptions is a question that needs further investigation and research.

One example of how cultural adjustment of language meaning functions is the use of home cultures in the teaching of idioms. At this level, the focus is on the encyclopaedic entry that learners draw when hearing idioms. Interestingly, there are two types of cultural adjustments: home cultural adjustment and second language cultural adjustment. The obstacle that 
learners may face is the second language cultural adjustment, because they might not be familiar with the cultural settings of the target language (this explains the target culture teaching based process that is discussed in the former section of the paper). For instance, (6) and (7) denote the cultural differences and the kind of cognitive loads that learners process in different cases when it comes to idiom comprehension.

(6) The French colonisation tried to buy off many great revolutionist characters.

(7) That politician bought an employee off because of a top confidential secret.

Example (6) is taken from Algerian history where the French colonisation at that time tried hard to bribe some famous revolutionist figures. Example (7) does not reflect the target cultures alone but it may take place everywhere around the world. For Algerian learners of English, example (6) might be easier to process than (7) because it carries assumptions about Algerian history which are part of Algerian culture. In example (6), the verb 'buy' activates the schematic information of bribery and temptation. Compared with (7) this may take a short time to process. The adjustment process, on the other hand, is also easier than before because learners in (6) adjust the meaning more quickly due to the contextual effects they are familiar with.

In other cases, there are the ostensive contextual effects that are added to build on the previously provided effects. Altering (6) slightly into (8) The French colonisation tried to buy off many great revolutionists characters with many tempting cars, villas and positions, (8) becomes well-established in terms of cognitive effects that can help learners to adjust the meaning of 'buy off' more quickly than in (6) because of the ostensive contextual effects of 'tempting cars, villas and positions'. Each of these is considered an ostensive contextual effect.

Now that the adjustment process of language and idioms is discussed, there are more explicit implications of the effects of target culture teaching practice in Algeria that are discussed in the next section.

\section{Teaching materials and linguistic imperialism in Algeria}

This section does not seek to blame the use of target cultures in Algerian classes of English but rather the unjustified use of target cultures when teaching English is under discussion. The main focus in this paper is beyond the linguistic imperialism and forms of language. It is about adopting ready-made teaching materials of English in Algeria and the effects this has on the teaching process. Teaching values of target cultures may not fit into classes where English is spoken as a second or foreign language. It is worth mentioning that there are different equivocal reasons for teachers to adopt target culture-based teaching materials in class. In my thesis, I urge the need 
for more research to unveil the causes of target culture teaching practice of English in Algeria (Bouherar, 2019). It is, however, unseemly to apportion blame on teachers as this may be linked to the type of teaching curriculum at the level of universities (Bouherar, 2019: 245). ${ }^{2}$

English linguistic imperialism, defined by Canagarajah (1999), is the English that is imposed on other institutions where the language and its cultural assumptions are seen as being superior to other languages and cultures. There are two forms of imperialism indicated in this definition: one is exerted via language and another via Anglo-Saxon cultures (whichever culture we might refer to ${ }^{3}$, i.e. American British, Australian...etc.). However, the critical issue here lies within the cultural imperialism policy in Algeria. English as a foreign language does not function outside the classroom opposed to the French language in Algeria. Algeria is influenced by French linguistic imperialism (Le Roux, 2017), and, to some extent, by French cultural imperialism.

Burchfield (1985) claims that there is a need for people to know and speak the English language as it is a type of linguistic deprivation if they do not. There are many implications derived from this claim. Speaking a language evokes the use of its cultures ${ }^{4}$ as claimed by the Sapir-Whorf hypothesis (Perlovsky, 2009). As a consequence, the spread of the English language delivers many implicit target culture-based assumptions to learners. If this is the case, how does this affect English learners around the world in general and Algerians in particular?

An example would be the British Council teaching materials that are used by many English teachers around the world. In the opening of a book (Integrating global issues in the creative English language classroom: with reference to the United Nations Sustainable Development Goals) by Maley \& Peachey (2017), published by the British Council, a teacher is asked about the teaching job in the classroom. The teacher replies that the work of a teacher should revolve around teaching learners about globalisation, exploitation, discrimination...etc. and how to think about these terms (Maley \& Peachey, 2017). Linguistic globalisation (UK essays, 2013) is the result of this ideological teaching which imposes certain cultural assumptions that often are not congruent with many teaching contexts. By this I mean, the use of English

\footnotetext{
${ }^{2}$ This, I believe, holds another aim of research that needs to be explored in different research papers than this one.

${ }^{3}$ Culture is a troublesome term that is intriguing in its features and components, if it has those 'fixed' components. However, in my humble efforts to set some terminological boundaries of culture, I can say that culture is language, religion, history, environment, traditions and everything we come to perform in our daily life practices according to our viewpoints that are very much determined by the mentioned terms.

4 The use of the plural in 'cultures' denotes more of an interpretive perspective to study culture.
} 
to sound more 'poshy' is a result of linguistic globalisation that usually brings with it the norms and traits of target cultures.

These observations do not seek to apportion blame to teaching materials designers around the world; rather, it is teachers', curriculum designers' and decision-makers' responsibility to choose what goes in line with the teaching context and respect learners' backgrounds. Phillipson (2010), in an interview on Al Jazeera English channel, argues that learners need to learn a form of English that expresses their own cultural identity and their specific needs.

\section{Methodology}

Hypothesis: I hypothesise that home cultures, when integrated in teaching idioms, can make comprehension and learning idioms easier than when integrated in target cultural teaching contexts. In other words, cultural contextual effects can add an extra cognitive effect to the process of comprehension: negative effects when not be familiar to learners or positive ones learners can understand in familiar cases. Without major cognitive effects, minor effects cannot stand alone but together they can add more extra effects and get learners to minimise their cognitive efforts with an adjustment process of idioms' meaning.

This project adopts mixed methods approach to collect data. The mixed methods involve semi-structured interviews with teachers and learners of English in Algeria and comprehension tests with students. According to Andrew \& Halcomb (2009), mixed methods adopt qualitative and quantitative data in one research scope and integrate the data in discussion the research. The results obtained from mixed methods are triangulated in form of comparing and contrasting the results of interviews with the results of comprehension tests. Triangulation is highly linked to mixed methods mainly in ways of analysing and interpreting data (Mertens \& Hesse-Biber, 2012).

Interviews about the teaching intervention aim to investigate learners' reactions and views to the lessons of idioms taught through home culture teaching strategy. The interview is divided into three parts: language, idioms and culture. Discussing idioms' teaching does not stand alone but it is linked to a more general framework of language teaching. The second part discusses the contextual assumptions idioms are embedded in and which components of culture learners were more interested in (history, religion, language ...etc.). The third part discusses culture and its importance in teaching idioms as far as teachers and learners in this research are concerned. To sum up, the interviews discuss how language teaching affects idioms teaching, the contextual assumptions that seem to attract learners to study and understand idioms and the cultural contexts that teachers and learners prefer to integrate when teaching and learning idioms. 
The analysis of the interviews follow a content analysis categorisation of codes to determine patterns and their relationship in the interviews (Vaismoradi, Turunen, \& Bondas, 2013). There are three major types of themes generated from analysing interviews' codes: global themes, organising themes, and basic themes. Global themes explains the general idea of the interviews. Organising themes show the major ideas that could be explored further under basic themes.

I developed some lessons to be taught throughout four weeks on an average of two sessions a week. Lessons include teaching idioms through home and target cultures using examples and contexts with multiple inferences. Comprehension tests were conducted after teaching the set of idioms intended in the form of pre- and post-testing. Comprehension tests investigate learners' improvement in idiom comprehension after the teaching intervention.

The two groups of learners, as indicated in table 1, were selected from two universities to ensure that they do not come in contact with each other. It is worth explaining that this is not an experiment, but rather a simple comprehension test. ${ }^{5}$

Table 1: Description of Comprehension Tests of the Participants

\begin{tabular}{|l|l|l|l|l|l|l|}
\hline Groups & Tests & $\begin{array}{l}\text { Number of } \\
\text { learners }\end{array}$ & Gender & Age & University name & City \\
\hline $\begin{array}{l}\text { Group 1 } \\
\text { Home } \\
\text { culture }\end{array}$ & Pre-test & 30 & Mixed & $20-22$ & $\begin{array}{l}\text { Mohamed Seddik } \\
\text { Ben Yahia }\end{array}$ & Jijel \\
\cline { 2 - 7 } & $\begin{array}{l}\text { Post- } \\
\text { test }\end{array}$ & 30 & Mixed & $20-22$ & $\begin{array}{l}\text { Mohamed Seddik } \\
\text { Ben Yahia }\end{array}$ & Jijel \\
\hline $\begin{array}{l}\text { Group 2 } \\
\text { Target } \\
\text { culture }\end{array}$ & Pre-test & 30 & Mixed & $20-22$ & $\begin{array}{l}\text { Mohamed Lamine } \\
\text { Dabaghine }\end{array}$ & Setif \\
\cline { 2 - 7 } & $\begin{array}{l}\text { Post- } \\
\text { test }\end{array}$ & 30 & Mixed & $20-22$ & $\begin{array}{l}\text { Mohamed Lamine } \\
\text { Dabaghine }\end{array}$ & Setif \\
\hline
\end{tabular}

\section{Comprehension tests analysis}

This section discusses the results of comprehension tests conducted with learners using the SPSS as an analytic software. Within this section, there are three subsections. One is the normality test which determines whether the population is naturally distributed and therefore what tests should be conducted (i.e. parametric and nonparametric tests). Second is the paired samples t-test and the third one is the independent samples t-test.

\footnotetext{
${ }^{5}$ As this is a qualitative approach of collecting data, the pillars of an experiment study are not met in such a social study that is purely human-based analysis with reactions and perspectives.
} 
Normality tests

Table 2: Tests of Normality

\begin{tabular}{|c|c|c|c|}
\hline Pre-test & & Statistic & Std. Error \\
\hline & Skewness & .393 & .309 \\
\cline { 2 - 4 } & Kurtosis & -.204 & .608 \\
\hline Post-test & & & .309 \\
\hline \multirow{3}{*}{} & Skewness & -.462 & .608 \\
\cline { 2 - 4 } & Kurtosis & -.189 & \\
\hline
\end{tabular}

Table 2 shows a descriptive result of the normality of the population of the study. In other words, it shows the normal distribution of the population. The type of normality test used is moment tests with skewness and kurtosis statistics (Thode, 2002). This table provides statistic and standard error of both pre-and post-tests. The normality of the population should be between (-1.96 to +1.96 ) (Osborn, 2006) and it has to be a positive or negative $\mathrm{z}$ value (Brysbaert, 2011). The $\mathrm{z}$ value is calculated in the next paragraph.

For table 2, SPSS provides the statistics and both skewness and kurtosis with their standard error values. Rose, Spinks \& Canhoto (2015) explain that in order to calculate the normality within the range of skewness/kurtosis statistic and standard error, we can divide the skewness/kurtosis on their standard error $(\mathrm{z}=$ statistic/standard error). They (2015) claim that in order to obtain results that show the normality of population, the $\mathrm{z}$ value has to be between $(-1.96$ and +1.96$)$. For the pre-test, the $\mathrm{z}$ value of skewness is $\mathrm{z}=1.271(\mathrm{z}=.393 / .309, \mathrm{z}=1.271)$. The $\mathrm{z}$ value of kurtosis is $\mathrm{z}=-0.335(\mathrm{z}=-.204 / .608, \mathrm{z}=-0.335)$. For the post-test, the $\mathrm{z}$ value of skewness is $\mathrm{z}=-1.495(\mathrm{z}=-.462 / .309, \mathrm{z}=-1.495)$. The kurtosis $\mathrm{z}$ value is $\mathrm{z}=-0.310(\mathrm{z}=-.189 / .608, \mathrm{z}=-0.310)$.

All the $\mathrm{z}$ values $(\mathrm{z}=1.271, \mathrm{z}=-0.335, \mathrm{z}=-1.495, \mathrm{z}=-0.310)$ are between +1.96 and -1.96 as shown. Therefore, the population of this study is normally distributed as there is equal variance within the population. In other words, the population is homogeneous. Homogeneity of variance means that there are equal learning chances for all learners in the population.

Based on the data results obtained from the normality test, the parametric test is conducted to measure the difference between group 1 and group 2 performance on idiom comprehension. 


\section{Paired samples T-test}

Table 3: Pre- and Post-Test Significance

\begin{tabular}{|c|c|c|c|c|c|c|c|c|}
\hline & \multicolumn{5}{|c|}{ Paired Differences } & \multirow{3}{*}{$\mathrm{t}$} & \multirow{3}{*}{ df } & \multirow{3}{*}{$\begin{array}{l}\mathrm{P} \\
\text { Value }\end{array}$} \\
\hline & \multirow[t]{2}{*}{ Mean } & \multirow[t]{2}{*}{$\begin{array}{l}\text { Std. } \\
\text { Deviation }\end{array}$} & \multirow[t]{2}{*}{$\begin{array}{l}\text { Std. } \\
\text { Error } \\
\text { Mean }\end{array}$} & \multicolumn{2}{|c|}{$\begin{array}{l}95 \% \text { Confidence } \\
\text { interval of the } \\
\text { difference }\end{array}$} & & & \\
\hline & & & & Lower & Upper & & & \\
\hline $\begin{array}{l}\text { Pre- } \\
\text { test- } \\
\text { Post- } \\
\text { test }\end{array}$ & -5.117 & 3.728 & .481 & -6.080 & -4.154 & -10.630 & 59 & .000 \\
\hline
\end{tabular}

Table 3 presents the paired sample test with the mean, standard deviation and the significance (p) of both pre-and post-tests, which is $\mathrm{p}=.000$.

It indicates the results of paired sample t-test. The mean is shown with a negative value $(\overline{\mathrm{x}}=-5.117)$ which indicates the difference between pre-and post-test mean values. The pre-test mean value is less than the post-test mean value. The total standard deviation sum of both pre-and post-test is $\mathrm{s}=3.728$. This means that the standard deviation of every learner's score is $\mathrm{s}=3.728$ before and after the teaching intervention. The standard error of the mean of both pre-and post-tests is se $=0.481$. There is also the confidence interval level of difference that is between -6.080 and -4.154 . This means that the mean difference $\overline{\mathrm{x}}=-5.117$ is between these two values of confidence. SPSS gives $95 \%$ confident interval level that learners' scores before teaching intervention will be lower than their scores after sitting for the lessons. Next, there is the $t$ value which is $-10,630$ and this is significant to $p<0.001$.

The table also means that there a high significance between pre- and post-test. This explains that learners' scores were better in the post-tests compared to the pre-tests.

\section{Independent samples T-test}

Table 4: Group 1 and 2 Significance

\begin{tabular}{|c|c|c|c|c|c|c|c|c|}
\hline Source & $\begin{array}{l}\text { Type III } \\
\text { sum of } \\
\text { squares }\end{array}$ & $\mathrm{df}$ & $\begin{array}{l}\text { Mean } \\
\text { square }\end{array}$ & $\mathrm{f}$ & Sig. & $\begin{array}{l}\text { Partial } \\
\text { Eta } \\
\text { Squared }\end{array}$ & $\begin{array}{l}\text { Noncent. } \\
\text { parameter }\end{array}$ & $\begin{array}{l}\text { Observed } \\
\text { power }^{b}\end{array}$ \\
\hline $\begin{array}{l}\text { Corrected } \\
\text { model }\end{array}$ & $98.817^{\mathrm{a}}$ & 1 & 98.817 & 7.945 & .007 & .120 & 7.945 & .792 \\
\hline Intercept & 1570.817 & 1 & 1570.817 & 126.298 & .000 & .685 & 126.298 & 1.000 \\
\hline Groups & 98.817 & 1 & 98.817 & 7.945 & .007 & .120 & 7.945 & .792 \\
\hline Error & 721.367 & 58 & 12.437 & & & & & \\
\hline Total & 2391.000 & 60 & & & & & & \\
\hline $\begin{array}{l}\text { Corrected } \\
\text { total }\end{array}$ & 820.183 & 59 & & & & & & \\
\hline
\end{tabular}

Table 4 presents the difference between groups' performance improvement on idiom comprehension at a significance value of $p=.007$. It 
contains different columns. Kirkpatrick and Feeney (2015) claim that unlike within-subjects test, between-subjects test has the significance test that is important to report. The significant value given by between-subjects test is $\mathrm{p}$ $=0.007$. This is less than the statistical significance value of this research, which is $0.05(\mathrm{p}<0.05)$. Therefore, the alternative hypothesis of this research, which states that there is a significant difference between group 1 and group 2 performance improvement on idiom comprehension, is accepted.

The results from the independent samples t-test indicate that the performance improvement of group 1 and group 2 differs considerably in terms of idiom comprehension. This means that there might be effects of home cultural context teaching strategy on learners' comprehension of idioms.

\section{Teachers' perspectives toward the teaching intervention}

There is one global theme of culture and teaching idioms under which there are three organising themes: teachers' integration and teaching practice of communicative approach, groups' reactions to the lessons as interpreted by their teachers, and the importance of cultural assumptions in teaching English and idioms. The first organising theme confirms the teaching approach teachers of both groups ${ }^{6}$ follow and unveils whether the lessons they taught to group 1 and 2 reflect the version of the communicative approach they adopt in class. This is because the lessons I designed were with reference to the communicative approach and this theme allows me to measure the extent to which lessons of both groups are seen as communicative by both teachers. This organising theme shares one basic theme: the communicative approach and culture (target/home) teaching.

Teachers claimed that the teaching strategy they used to teach idioms in class (i.e. target culture teaching strategy and home culture teaching strategy) throughout the teaching intervention reflects the teaching approach they follow (i.e. the communicative approach) and serves their teaching aims and objectives in class. However, there are differences in the degree of difficulty of the idioms taught in class by the two teachers.

Idioms were not difficult except that the meaning of idioms is not understood at the literal level so the surface structure sometimes is quite misleading so we have to read the deep structure or what is the meaning behind. When I teach students idioms I say we are not supposed to understand words by words but the whole structure rather than by words (Lydia, Appendix Three, lines: 7-10). 'No they were simple', (Jamila, Appendix Four, line 6).

\footnotetext{
${ }^{6}$ Teachers of both groups are referred to differently in this paper: home culture group teacher to refer to the teacher who taught home culture group (named Jamila in this article). Target culture group teacher to refer to the teacher who taught target culture group (named Lydia in this article).
} 
The extract above may not seem related to the nature of this theme but it reveals the teaching practice of teachers through the teaching of idioms as both teachers declared that the teaching strategy they used during teaching reflect the teaching approach they follow. If this is so, both teachers could have reported the same statement about teaching difficulty, which does not seem to be the case. It is clear from the extracts that teachers did not have the same teaching experience when delivering idioms to learners as it seems that idioms were somewhat difficult to teach for Lydia compared to Jamila. The difficulty faced by Lydia could be due to the target-culture target cultural assumptions delivered with idioms.

This means that there are different understandings and implementations of the principles of the communicative approach in class, particularly CBA. When looking at the communicative approach teaching principles, there is one principle that encourages teachers to link classroom activities with learners' daily life (Sreehari, 2012). Having said this, Jamila intends to reflect the learning environment of learners in the class, to some extent, while Lydia has different thoughts about the learning environment of learners and its impact on class teaching. The target culture does not function in Algerian learners' society and therefore only a few students make good use of it through the internet or other means of communication.

The second organising theme explores groups' reactions to the lessons as interpreted by their teachers. This theme contains two basic themes: target culture group negative reactions to the lessons and home culture group's positive reactions to the lessons. Learners' reactions to the teaching intervention differ considerably between groups. For the target culture-based group, the teacher claimed that learners did not seem interested in the content of the lessons she taught.

Our learners are used to learn idioms and I like to teach language in a context. They were accustomed to learning idioms. Always when I teach oral expressions I have to pass by idioms (Lydia, Appendix Three, lines: 3-5).

It seems that the teacher did not want to answer the question directly but instead she inferred that her learners are very used to the teaching of idioms. The implication from her statement is that teaching was easy for her learners but this is not what the comprehension tests results showed.

The second basic theme shows home culture group's positive reactions to the lessons. The interviews conducted with the two teachers after the teaching practice finished revealed that group 1 manifested a willingness to learn the lessons. They wanted the lessons to last longer and this may clarify that learners were comfortable with the new lessons. 
'They told me "Mrs is it going to stay a bit longer?" Yea, they were so interested and they liked it so much', (Jamila, Appendix Four, lines: 34).

This extract indicates leaners' positive reactions to the lessons. The teacher confirms her learners' commitment with lessons in class. There are congruent thoughts between Jamila and her learners concerning their reactions to the lessons (see the first basic theme in the first organising theme effects of cultural assumptions on learning idioms, learners' interviews in the next section). This shows that the content of the lessons group 1 had were easy and accessible to learners and their teacher. Evidently, integrating home cultural contexts in teaching can benefit learners in class as opposed to target culture teaching materials/practice that targets a minority of learners as discussed through the ideas of Lydia.

The third organising theme is about the importance of cultural assumptions in teaching English and idioms. This theme contains two basic themes: the importance of home culture in teaching idioms and the importance of target culture in teaching English. There are different thoughts between both teachers about the culture that should be integrated to teach idioms and English. There was a high recommendation of using the Algerian home cultures, especially by Jamila.

Of course much related to the culture they are familiar with because they do not know much about the target culture. It is better to embed it within the home culture (Jamila, Appendix Four, lines: 21-22).

It is much better to form a kind of balance, much better, so that the students will develop competence gradually and simultaneously with the target culture. A kind of balance is good (Jamila, Appendix Four, lines: 35-37).

Jamila recognised the significant role home cultural assumptions played in idiom comprehension for her class during those four weeks. Because of the positive reactions she received during teaching, she thinks that home culture teaching could be beneficial to idiom teaching as a teaching strategy.

Her statement might be due to the positive results she witnessed in class with her students during four weeks of empirical work. The need to teach idioms through home cultures does not necessarily require complete neglect of target culture since culture and language are inextricable. It is, indeed, implausible to neglect target cultures in class but rather display reasonable target cultural assumptions for learners.

Jamila's claim does not neglect target cultures to be taught in class but the positive effects of home cultures seem to be more influencing and beneficial to learners and their teacher. 
The second basic theme presents the importance of target culture in teaching language. In this theme, both teachers claim that target culture teaching is essential for teaching idioms and English in general.

'I teach English as it is not as it should be', (Lydia, Appendix Three, line 24).

Also, I teach slang language that many teachers are against teaching it. I like to put my students in authentic setting, this is how they think, how they do and so on, even gestures, gazing, touching so this is also language (Lydia, Appendix Three, lines: 37-40).

'...once you do not know about the culture you cannot know what to speak and how to speak', (Jamila, Appendix Four, lines: 17-18).

This theme stresses the significance of teaching target culture to learners and its essential role in English teaching. This theme may hold contradictory arguments to the first basic theme of the communicative approach and culture (target or home) teaching in the first organising theme and to the first basic theme of the importance of home culture in teaching idioms in the third organising theme of this section.

Teachers claimed that target culture is the key for learners to understand English. Lydia (see Appendix Three) complained about high school syllabus that teaches Algerian culture using English with little reference to the target cultures. She claimed that there is no point at all in teaching home cultures and they lead learners to nowhere.

Many threatening elements endanger learning English idioms through target cultures. First of all, the input that learners receive every day about target cultures outside the classroom may not be the same with what teachers teach in class or with what is depicted in teaching materials as target cultures. If a target culture is suggested in the class to teach idioms or English, then, what sort of a target culture teachers aim to integrate? Apparently, there are different target cultures and sometimes the ones depicted in teaching textbooks or any teaching materials may not truly describe the culture(s) sought to be taught.

Also, teachers claim about the beneficial use of target culture in class might be due to the influence of ready-made teaching materials that some teachers adopt in class which contain different target cultural assumptions.

It seems that both teachers agree that target culture-based methods can result in a better understanding of idioms and English in general. Jamila, however, expressed a positive tendency towards home cultures in teaching idioms. This could be due to her teaching experience throughout the empirical work, where she claimed that she witnessed some positive reactions from her students. Lydia, however, seem to resist the fact that her class was not really responsive and willing to learn idioms due to the target cultural assumptions 
that are difficult to process. In the next section, I discuss learners' reactions to the teaching intervention.

\section{Learners' views on the teaching intervention}

Learners' interviews contain one global theme: aspects of teaching idioms through home culture, under which there are two organising themes: Effects of cultural assumptions on learning idioms and learners' preference for the use of home culture and L1 in class. The first organising theme contains two basic themes: first, learners' positive views on the lessons and second, the advantages of using home culture in learning and the positive effects of familiar contextual assumptions on idiom understanding. Interviews conducted with learners showed that all learners who were interviewed reported that the lessons they had were interesting and useful for them as they claimed that the method of teaching idioms is a better alternative.

'They were really exciting', (Zeyneb, Appendix Five, line 3), 'they were interesting and easy', (Samira, Appendix Six, line 3), 'I found them really interesting and I enjoyed them actually', (Ahlam, Appendix Seven, line 3), 'yes I found them beneficial, useful and good', (Safia, Appendix Eight, line 3), 'I think they were interesting', (Leyla, Appendix Nine, line 3), 'I think they are the most interesting lessons I have had. We have studied idioms before but not this way', (Ahmed, Appendix Ten, lines: 3-4).

Again, these extracts confirm Jamila's claim (this can be found in the second basic theme of home culture group positive reactions to the lessons, the second organising theme, see the previous section) that her learners enjoyed the lessons.

Learners posited that they felt comfortable with the lessons and said that those lessons might be also helpful to other students at their level. The main reason they found the lessons interesting is that the context they were embedded in was clear and easy to process. Also, the positive attitude of learners reveals that the learning context can be a great source of help to learners.

The easy-processed assumptions embedded through home cultures helped learners to gain easy access to the encyclopaedic assumptions of idioms. This theme resonates with Jamila's views on the classes she taught during four weeks: she claimed that learners had very positive attitudes towards the lessons. Besides, comprehension tests also showed positive results of learners' performance improvement on idiom comprehension (see comprehension tests analysis Section).

The second basic theme is related to the advantages of using home culture in learning and the positive effects of familiar contextual assumptions 
on idiom understanding. Because learners found home cultures helpful in learning idioms, they stated that they should have recourse to home cultures to learn idioms as they help them to retain and understand such expressions.

'I think we should use context familiar to learners', (Zeyneb, Appendix Five, line 20).

Yes of course it must be related to our culture because when it is related to our culture you will remember them easily and you are not going to forget them (Samira, Appendix Six, lines: 14-15).

'Of course examples that suit life and situations this will help us so much to understand idioms', (Ahlam, Appendix Seven, lines: 16-17), 'the context that is familiar to us and because it is easy to understand', (Safia, Appendix Eight, line 11).

I think it is the context that is familiar to us because it facilitates to get the meaning quickly and to understand what the idiom means exactly (Leyla, Appendix Nine, lines: 17-18).

'Familiar context to our culture because it is something new to me. First, we have to understand the meaning through using familiar context', (Ahmed, Appendix Ten, lines: 13-14).

Learners indicate the importance of familiar contexts in learning idioms that are oriented towards home cultures in lessons. The familiarity of the contexts based on Algerian cultural assumptions played a significant role in clarifying the meaning of idioms. This suggests that autochthonous cultural assumptions might result in a better understanding of idioms if integrated into the class.

The familiar assumptions seemed to have better effects than the schematic target culture-based assumptions. Context acts as a facilitator and provides easy access to the meaning of idioms. This is because the human mind is designed to look for easy-processing assumptions with high relevance contexts to the hearer as claimed in relevance theory (see Wilson and Sperber 2004). This is congruent with the principle of the communicative approach that learning is expected to go hand in hand with learners' interests and needs.

This basic theme is another evidence that home cultures can facilitate the process of learning and understanding idioms compared to assumptions of target culture.

On a similar level, all learners agreed that the context that idioms were embedded in acted as a facilitator in learning idioms. They also think that the examples provided with idioms were crucial for the comprehension process.

'Also when she gave example you know and you do it before this helps you to memorise it', (Ahlam, Appendix Seven, lines: 22-23), 'yes, I did think of familiar examples', (Leyla, Appendix Nine, line 21), 'what I found interesting about those lessons is examples that were familiar 
with our culture and helpful for understanding idioms', (Ahmed, Appendix Ten, lines: 4-5).

The examples given by the teacher helped learners to process helpful assumptions about the meaning of idioms. These examples create schemas that learners sometimes rely on to access the meaning of idioms. Within target cultures, the cultural contexts may not help learners to remember the meaning because it is difficult to link particular schemas to the meaning as the item and the source are not directly motivated in memory. With home cultural context teaching, however, it is different. The connection between the item and the source creates schemas that are automatically remembered/activated with certain familiar examples/contexts of home cultures. This is why learners claimed that examples and contextual assumptions linked to idioms helped them to gain easy access to the meaning. One of the learners (Ahmed) I interviewed said he thought of similar schemas when he heard the teacher saying 'he gets the best of both worlds, he came back to see family and enjoy the moment of Ramadan at home'. Ahmed said and I quote him:

Yes they came to my mind directly. I think about something else, something quite related to religion about the two lives and life after death and if you do something good you get both lives and if you do something bad .... (Ahmed, Appendix Ten, lines: 17-19).

The second organising theme is learners' preference for the use of home culture and L1 in class. It shares two basic themes: one is learners' views on teaching target culture compared with home culture and the second is home culture and L1 interference in learning English and idioms. Learners claimed that learning English and idioms should be linked to home cultures.

'In class we have to use our culture to understand English in general', (Ahlam, Appendix Seven, lines 37), 'I dislike this kind of teaching. I prefer to teach language without the culture because I hate it', (Safia, Appendix Eight, lines: 7-8), 'yes sometimes we need that to facilitate the learning process because home culture helps you to remember and understand in the same time', (Safia, Appendix Eight, lines: 32-33), 'just little bit to... if we want for example to travel to English countries so it will help us to communicate with them', (Leyla, Appendix Nine, lines: 12-14), 'there is always something in their culture that we do not accept it so I do not think we should focus on target culture a lot', (Leyla, Appendix Nine, lines: 35-37).

These extracts show the negative attitudes of learners towards target culture-based teaching. There is a clear preference among learners for home cultures teaching practice instead. They consider home cultures more 
convenient for them. This positive reaction to home culture teaching could be due to the lessons that learners studied for four weeks. Compared with what learners used to work with prior to the lessons (i.e. target cultures based teaching practice), home cultural contexts might have provided learners with precise encyclopaedic routes of comprehension that could lead them to the intended meaning of idioms. In contrast to this, learners' negative reactions might be caused by the unfamiliarity of cultural assumptions resulting from target culture teaching practice. This can result in a difficulty to understand idioms which can be manifested in the failure to link target cultural assumptions with the current schematic information of learners ending in a misunderstanding of such expressions.

The second basic theme is related to home culture and L1 interference in learning English and idioms. Learners claimed that there was an extensive use of L1 and home cultures in class as this also helped them to learn English in general.

When I chose to learn English I put in my mind that I am going to learn this language as a second language and I do not erase that I have my mother tongue and I have my own culture (Zeyneb, Appendix Five, lines: 44-46).

When I think about it in my L1 I will try to transform it to English language and this makes it easy for me to understand (Samira, Appendix Six, lines: 31-32).

'Yes L1 is helping too much to understand to remember idioms and to memorise them', (Ahlam, Appendix Seven, lines: 32-33), 'home culture helps you to remember and understand in the same time', (Safia, Appendix Eight, lines: 32-33).

In line with the previous theme, this theme acknowledges L1 and home cultures in teaching idioms and English. Learners concluded that learning could be more accessible (i.e. easier) if home cultures and L1 are used regularly in class and are acknowledged by their teachers.

Learners seemed to rely on mediation in learning (Canagarajah, 1999) by resorting to their L1 when they come across something difficult to understand. They claimed that the excessive use of L1 helped them in learning and comparing idioms to their L1 equivalents. This means that the use of home cultural lessons could, to a more considerable extent, bring significant results to the majority of learners in class as far as learning idioms is concerned.

'There is always something in their culture that we do not accept it', (Leyla, Appendix Nine, lines: 35-36).

This is one of the learners' statements about target cultures teaching practice in class. Because the role of L1 and home cultures in class is 
significant to the process of learning, learners expressed their need to integrate them in class. This could be due to the easy processing assumptions provided through the use of home cultures and the sense of security and belonging of learners when they use L1 in class, especially for beginners.

There is a need to balance target and home cultures teaching practice. As stated previously, the focus on target culture teaching practice makes learning difficult because the teacher has to explain both idioms and the accompanying target cultural contexts for learners. However, home cultural contexts may help and guide learners to related assumptions about idioms through familiar examples they know which also connect to other easyprocessing schematic information retained automatically. ${ }^{7}$

Almost all themes discussed with reference to learners thoughts about integrating home cultures to teach idioms and English are positive because of different reasons. First, the encyclopaedic assumption of idioms drawn by learners in different scenarios (home and target cultures) are not the same. Home cultural encyclopaedic assumptions are a stimulus to easy-access to idioms' meaning while target cultural encyclopaedic assumptions are a deterrent to idioms' comprehension. Second, these encyclopaedic assumptions are always linked with familiar schematic information provided through examples in the lessons which learners seemed to enjoy. Third, because the human mind is guided toward relevance according to relevance theory, learners access home cultural assumptions faster than target cultural assumptions. All these reasons can justify learners' positive reactions to the lessons that assumed home culture.

When comparing the results of teachers' and learners' findings, I would say that there are some differences between teachers' and learners' interviews conducted with reference to the teaching intervention. First of all, it seems that target culture is highly ranked in teachers' teaching materials but very few learners reported positive feedback about learning due to unfamiliar cultural assumptions. Second, because of this, it is more likely to assert that there is a form of linguistic or cultural imperialism in class. It is made even clearer by the teachers' and learners' different preferences about using L1 and home cultures in the class: teachers intend to have more restrictions on learners' using L1 and home cultures, while learners find them more helpful in learning. Thirdly, learners highly recommended the use of home cultures in teaching materials in class as they claimed this helps them in learning but teachers seemed, arguably, reluctant to acknowledge this.

\footnotetext{
${ }^{7}$ This paper does not hold a firm claim that learners should only learn idioms that relate to their home cultures but rather link idioms with accessible contextual assumptions that can be easy for learners to understand.
} 


\section{Conclusion and Recommendations}

This research paper revealed positive outcomes of home cultures on understanding idioms. Semi-structured interviews provided learners' positive thoughts about the use of home cultures compared with target cultures. Comprehension tests, on the other hand, showed that idioms embedded in home cultural contexts were easier to process and understand than idioms embedded in target cultural contexts.

Although this paper provided different arguments that home cultural assumptions in teaching English and idioms, in particular, can lead to better results, there is still some ambiguity about what exactly encourages teachers to consider target culture teaching practice in class. The communicative approach principle of authentic materials inclusion in teaching English is vague. The value of authenticity in teaching, according to the communicative approach, should also be discussed further.

There are different possibilities and implications that can be discussed further in other potential research papers: the curriculum of teaching English at the level of universities, the ideology behind teaching English and the readymade teaching materials integrated in classroom.

\section{References:}

1. Andrew, S \& Halcomb, E. (2009). Mixed method research for nursing and the health sciences. Oxford: Blackwell.

2. Bouherar, S. (2017). Idiom understanding and teaching: do we need to assume a target culture? Theory and practice in language studies, 7, 11, 943-951.

3. Bouherar, S. (2019). Understanding and teaching idioms: Arguments for assuming home cultural contexts in teaching materials. $\mathrm{PhD}$ thesis. Middlesex University, London, UK.

4. Brysbaert, M. (2011). Basic statistics for psychologists. London: Palgrave Macmillan.

5. Burchfield, R. W. (1985). The English language. Oxford: Oxford University Press.

6. Canagarajah, A. S. (1999). Resisting linguistic imperialism in English teaching. , Oxford: Oxford University Press.

7. Clark, B. (2013). Relevance theory. Cambridge: Cambridge University Press.

8. Ferraro, G., \& Andreatta, S. (2014). Cultural anthropology: An applied perspective. $10^{\text {th }}$ edn. Stamford, CT: Cengage Learning.

9. Kirkpatrick, L. A. \& Feeney, B. C. (2015). A simple guide to IBM SPSS statistics. Boston: MA: Cengage Learning. 
10. Le Roux, C. S. (2017). Language in education in Algeria: a historical vignette of a 'most severe' sociolinguistic problem. Language and History, 60, 2, 112-128.

11. Maley, A., \& Peachey, N. (2017). Integrating global issues in the creative English language classroom: with reference to the United Nations Sustainable Development Goals. London: British Council.

12. Mertens, D. M., \& Hesse-Biber, S. (2012). Triangulation and mixed methods research: provocative positions. Journal of Mixed Methods Research 6, 2, 75-79.

13. Osborn, C. E. (2006). Statistical applications for health information management. $2^{\text {nd }}$ edn. London: Jones and Bartlett Publishers.

14. Perlovsky, L. (2009). Language and emotions: Sapir-Whorf hypothesis. Neural Network, 22, 518-526.

15. Phillipson, R. (2010). (2019, December 20). Riz Khan - linguistic imperialism? Retrieved from: https://www.youtube.com/watch?v=c3TJe4jnqFo.

16. Rose, S., Spinks, N., \& Canhoto, A. I. (2015). Management research applying the principles. London: Routledge.

17. Sreehari, P. (2012). Communicative language teaching: possibilities and problems. English Language Teaching, 5, 12, 87-93.

18. Thode, H. C. JR. (2002). Testing for normality. New York: Marcel Dekker.

19. UK Essays (2013). A threat to the diversity of languages English language essay. Retrieved from: https://www.ukessays.com/essays/english-language/a-threat-to-thediversity-of-languages-english-language-essay.php?cref $=1$.

20. Vaismoradi, M., Turunen, H., \& Bondas, T. (2013). Content analysis and thematic analysis: implications for conducting a qualitative descriptive study. Nursing and Health Sciences 15, 398-405.

21. Vega Moreno, R. E. (2007). Creativity and convention: The pragmatics of every day figurative speech. Amsterdam: John Benjamins Publishing Company.

22. Wilson, D., \& Sperber, D. (2004). Relevance theory. In Horn, L. R., \& Ward, G. (eds.), The handbook of pragmatics (pp. 607-632). Malden: MA: Blackwell. 


\section{Appendices}

\section{Appendix 1: teachers' interview}

Interview guide for teachers

This interview is meant to discover some points of view of how second language teachers think of the process of learning a second language in general and idioms in particular. Their points of view would improve the process of teaching and learning. The participants who gave their consent to participate in this study have been explained all anonymity/ethical issues. The interview takes approximately 20 to 30 minutes.

\section{Language}

1. Which strategy do you think was more effective?

2. What was the students in each group's reaction to the new lessons (i.e. which group was active and willing to learn more)?

3. Did you face any difficulty in teaching idioms to both groups? What was it?

4. What kind of teaching approach do you adopt in class (i.e. is it communicative approach, audio-lingual approach ... etc.)?

5. Which strategy you think may reflect the teaching approach you are following in class? Why?

6. What do you think of culture in language teaching, is it a must? Then, what sort of culture are you looking at in teaching?

Idioms

1. What context do you think idioms should be embedded in to facilitate the process of learning them?

2. Some idioms were embedded in historical cultural contexts, others were embedded in religious cultural contexts and some others simulated the environment, which one of these cultural bits was very effective in terms of comprehension and accessibility of idiom's meaning when you taught them to group 1 and 2 ?

Culture

1. Did you feel the necessity to elaborate a little bit on the cultural context used in those idioms or was it clear for learners? Why?

2. Were you somewhat obliged to use learners' home culture in target culture group and vice versa? If you were, was that helping learners with something?

3. Some teachers claim that we need to move forward from target culture teaching based-practice and we need to balance that with home culture teaching based-practice? What do you think? 


\section{Appendix 2: students' interview}

Interview guide for students

This interview is meant to discover some points of view on how second language learners think of the process of learning a second language in general and idioms in particular. Their point of views would improve the process of teaching and learning. The participants who gave their consent to participate in this study have been explained all anonymity/ethical issues. The interview takes approximately 20 to 30 minutes.

Language

1. How did you find the new lessons so far, (i.e. useful, not really beneficial ... etc.)?

2. Did you encounter difficulty in understanding the idioms of each lesson? Why?

3. Do you think these lessons, especially bits of idioms, might be helpful to other students at your level who are dealing with idioms a lot in class? Why?

4. What do you think of culture in language teaching, is it a must? Then, what sort of culture are you looking at in teaching?

Idioms

1. What context do you think idioms should be embedded in to facilitate the process of learning them?

2. What kind of schemas (ideas) that came across your mind when you heard idioms are embedded in a context during lessons you were taught?

3. Did those schemas help you to make sense of idioms? Why?

4. Some idioms were embedded in historical cultural contexts, others were embedded in religious cultural contexts and some others simulated the environment, which one of these cultural bits was very effective in terms of comprehension and accessibility of idiom's meaning to you?

Culture

1. Did you feel the necessity to elaborate a little bit on the cultural context used in those idioms or was it clear for you? Why?

2. Why do you think using home culture may or may not help in getting a better comprehension of idioms than target culture?

3. Some teachers claim that we need to move forward from target culture teaching based-practice and we need to balance that with home culture teaching based-practice? What do you think? 


\section{Appendix 3: Lydia interview}

Interviewer: How was students' reaction in each group to the new lessons (i.e. which group was active and willing to learn more)?

Interviewee: our learners are used to learn idioms and I like to teach language in a context. They were accustomed to learn idioms. Always when I teach oral expressions I have to pass by idioms.

Interviewer: Did you face any difficulty in teaching idioms with this group? What was it?

Interviewee: idioms were not difficult except that the meaning of idioms is not understood at the literal level so the surface structure sometimes is little bit misleading so we have to read the deep structure or what is the meaning behind. When I teach students idioms I say we are not supposed to understand words by words but the whole structure rather than by words.

Interviewer: What kind of teaching approach are you adopting in class (i.e. is it communicative approach, audio-lingual approach ... etc.)?

Interviewee: I follow the communicative approach.

Interviewer: does this strategy reflect the teaching approach you are following in class? Why?

Interviewee: for sure. In the Algerian context of teaching we have adopted the CBA from 2002/2003 and this is mean by the end of their career as students learners are supposed to be competent communicators outside the institutional settings. Language reflects its culture. We are looking to the pragmatic competence (target culture competence). We seek fluent learners rather than grammarians. The problem in learning languages is we think Arabic but we speak French or English. So the cultural norms of the other must be respected in teaching, there are some similarities but we have to insist on differences.

Interviewer: In what context do you think idioms should be embedded in to facilitate the process of learning them?

Interviewee: I teach English as it is not as it should be. Language in context as it is spoken by its native speakers. I was teaching in high school and they said you have to simplify your English, I said how shall I do so? I like to raise my learners' awareness about the similarities but in the same time this language has its specific things.

Interviewer: have taught those idioms before?

Interviewee: yes, I have taught some of them before and others are quite new. Interviewer: Were you somewhat obliged to use learners' home culture in target culture group and vice versa? If you were, was that helping learners with something?

Interviewee: there are some similarities yes but there are also differences. We have different language, different culture, different environment, different mentality, different thinking. You see here in the French or English department how they put clothes their hair style and so on, I like to see these things as if 
they are imitating the "other" they like to be like the "other". I have to benefit from this, it means the learner want to be an English speaker or native speaker. Give them language as it is. I like to take the learner and put him in the language bath. Also I teach slang language that many teachers are against teaching it. I like to put my students in authentic setting, this is how they think, how they do and so on, even gestures, gazing, touching so this is also language.

\section{Appendix 4: Jamila interview}

Interviewer: How was students' reaction in each group to the new lessons (i.e. which group was active and willing to learn more)?

Interviewee: they told me Mrs is it going to stay a bit longer? Yea, they were so interested and they liked it so much.

Interviewer: Did you face any difficulty in teaching idioms in both groups? What was it?

Interviewee: no they were simple because I just have the habit of teaching idioms.

Interviewer: What kind of teaching approach are you adopting in class (i.e. is it communicative approach, audio-lingual approach ... etc.)?

Interviewee: I am adopting the communicative approach in class.

Interviewer: Which strategy you think may reflect the teaching approach you are following in class? Why?

Interviewee: kind of, yeah. Because I always relate idioms to communicative activities. But yeah it really serves my objective of teaching.

Interviewer: What do you think of culture in language teaching, is it a must? Then, what sort of culture are you looking at in teaching?

Interviewee: it is. I mean you are not going to speak that kind of academic language outside. I mean of course the language is quite related to the culture so once you do not know about the culture you cannot know what to speak and how to speak.

Interviewer: In what context do you think idioms should be embedded in to facilitate the process of learning them?

Interviewee: of course much related to the culture they are familiar with because they do not know much about the target culture. It is better to embed it within the home culture.

Interviewer: Some idioms were easy for learners to guess as I have noticed, do you know why?

Interviewee: maybe because they have studied those idioms before because they are just in their second year so they still not familiar with idioms, they must've come across those idioms somewhere.

Interviewer: Were you somewhat obliged to use target culture? 
Interviewee: yes sometimes. It depends, sometimes it goes within the knowledge they have about the target culture and sometimes beyond their knowledge and it requires some explanation from my part.

Interviewer: Some teachers claim that we need to move forward from target culture teaching based-practice and we need to balance that with home culture teaching based-practice? What do you think?

Interviewee: It is much better to form a kind of balance, much better, so that the students will develop competence gradually and simultaneously with the target culture. A kind of balance is good.

\section{Appendix 5: Zeyneb interview}

Interviewer: How did you find the new lessons so far, (i.e. useful, not really beneficial ... etc.)?

Interviewee: they were really exciting because I am interested in idioms and they helped in speaking and I use them as much as possible. Also they show that a speaker has a good control over the language.

Interviewer: Did you find difficulty understanding idioms of each lesson? Why?

Interviewee: some of them are difficult yes. Like what we have seen this session I cannot even expect the meaning of some idioms but some others were easy.

Interviewer: Do you think these lessons especially bits of idioms might be helpful to other students at your level who are dealing with idioms a lot in class? Why?

Interviewee: I would recommend those lessons to other learners in my level because I found them helpful.

Interviewer: do you think integrating idioms in target culture may or may not help learners to understand idioms?

Interviewee: it may help, to know the language of others you must learn their culture because the language is part of culture and to speak the language very well you must be aware of their culture but limits and not fully learning the culture.

Interviewer: In what context do you think idioms should be embedded in to facilitate the process of learning them?

Interviewee: I think we should use context that is familiar to learners because when we use them in a context that is known for us we can expect the meaning and we can learn them easily.

Interviewer: What kind of schemas (ideas) that came across your mind when you hear idioms that are embedded in a context when you were taught those new lessons?

Interviewee: yes some of them, Ramadan schemas.

Interviewer: Did those schemas help you to make sense of idioms? Why? 
Interviewee: Those schemas helped to understand idioms. When we run across an idiom we do not know, from the context it is embedded in we can understand the meaning of it.

Interviewer: Some idioms were embedded in historical cultural contexts, others were embedded in religious cultural contexts and some others simulated the environment, which one of these cultural bits was very effective in terms of comprehension and accessibility of idiom's meaning to you?

Interviewee: I can't remember but there were some idioms easy for me to understand because I like learning idioms and when you do something you love you do not find difficulty learning it or memorising it.

Interviewer: Did you feel the necessity to elaborate a little bit on the cultural context used in those idioms or was it clear for you? Why?

Interviewee: yes sometimes. Sometimes we find something exist in our language, we turn back to our first language to find an equivalent to this in order to find the meaning. our mother tongue is a shelter in learning.

Interviewer: Some teachers claim that we need to move forward from target culture teaching based-practice and we need to balance that with home culture teaching based-practice? What do you think?

Interviewee: when I chose to learn English I put in my mind that I am going to learn this language as a second language and I do not erase that I have my mother tongue and I have my own culture. I do not have any problem in learning new things or being aware of other cultures but not to be totally part of their culture.

\section{Appendix 6: Samira interview}

Interviewer: How did you find the new lessons so far, (i.e. useful, not really beneficial ... etc.)?

Interviewee: they were interesting and easy

Interviewer: Did you find difficulty understanding idioms of each lesson? Why?

Interviewee: they fall in a continuum of easiness and difficulty.

Interviewer: Do you think these lessons especially bits of idioms might be helpful to other students at your level who are dealing with idioms a lot in class? Why?

Interviewee: I do yes, because they were easy.

Interviewer: What do you think of target culture integration in teaching English here?

Interviewee: I think it is very important because in the future if you want to travel to another country like Britain you have to know their culture their habits and customs.

Interviewer: In what context do you think idioms should be embedded in to facilitate the process of learning them? 
Interviewee: yes of course it must be related to our culture because when it is related to our culture you will remember them easily and you are not going to forget them.

Interviewer: What kind of schemas (ideas) that came across your mind when you hear idioms that are embedded in a context when you were taught those new lessons?

Interviewee: yes I did because they are related to our culture.

Interviewer: Did those schemas help you to make sense of idioms? Why?

Interviewee: yes of course, when the teacher writes those expressions with reference to our culture it helped us a lot to remember those idioms easily and without any difficulty.

Interviewer: Some idioms were embedded in historical cultural contexts, others were embedded in religious cultural contexts and some others simulated the environment, which one of these cultural bits was very effective in terms of comprehension and accessibility of idiom's meaning to you?

Interviewee: yes some idioms were easier than other, maybe because I have studied them before. But I can't remember the bits of culture that were effective to create easy context for me to understand idioms.

Interviewer: Did you feel the necessity to elaborate a little bit on the cultural context used in those idioms by using L1 or finding equivalents? Did this help? Interviewee: yes it does help me very much because when I think about it in my L1 I will try to transform it to English language and this makes it easy for me to understand.

Interviewer: Why do you think using home culture may or may not help in better comprehension of idioms than target culture??

Interviewee: no I do not think it may help us in learning idioms because idioms are quite different from our culture. I think we should focus on target culture to teach idioms because language and culture are interconnected.

\section{Appendix 7: Ahlam interview}

Interviewer: How did you find the new lessons so far, (i.e. useful, not really beneficial ... etc.)?

Interviewee: I found them really interesting and I enjoyed them actually.

Interviewer: Did you find difficulty understanding idioms of each lesson? Why?

Interviewee: some of them were quite difficult maybe because they are new or something like that.

Interviewer: Do you think these lessons especially bits of idioms might be helpful to other students at your level who are dealing with idioms a lot in class? Why?

Interviewee: yes of course because they are interesting I can recommend them to other students in my level. 
Interviewer: What do you think of teachers who focus a lot on the target culture in class?

Interviewee: maybe it is a good thing to understand others' culture. Maybe there, when you go there it will help you.

Interviewer: In what context do you think idioms should be embedded in to facilitate the process of learning them?

Interviewee: of course examples that suit life and situations this will help us so much to understand idioms.

Interviewer: What kind of schemas (ideas) that came across your mind when you hear idioms that are embedded in a context when you were taught those new lessons?

Interviewee: yes all those schemas interfere together.

Interviewer: Did those schemas help you to make sense of idioms? Why?

Interviewee: of course they are really helpful to remember and perform them. Also when she gave example you know and you do it before this helps you to memorise it.

Interviewer: Some idioms were embedded in historical cultural contexts, others were embedded in religious cultural contexts and some others simulated the environment, which one of these cultural bits was very effective in terms of comprehension and accessibility of idiom's meaning to you?

Interviewee: yes some idioms were easy and I cannot remember the bits of cultures exactly but the context they were in helped me to understand them.

Interviewer: Did you feel the necessity to elaborate a little bit on the cultural context used in those idioms by using L1 or finding equivalent? Did it help?

Interviewee: yes L1 is helping too much to understand to remember idioms and to memorise them.

Interviewer: Some teachers claim that we need to move forward from target culture teaching based-practice and we need to balance that with home culture teaching based-practice? What do you think?

Interviewee: in class we have to use our culture to understand English in general.

\section{Appendix 8: Safia interview}

Interviewer: How did you find the new lessons so far, (i.e. useful, not really beneficial ... etc.)?

Interviewee: yes I found them beneficial, useful and good.

Interviewer: Did you find difficulty understanding idioms of each lesson? Why?

Interviewee: yes some of them difficult but the rest are easy.

Interviewer: What do you think of teachers focusing on target culture in class? Interviewee: I dislike this kind of teaching. I prefer to teach language without the culture because I hate it. 
Interviewer: In what context do you think idioms should be embedded in to facilitate the process of learning them?

Interviewee: the context that is familiar to us and because it is easy to understand.

Interviewer: What kind of schemas (ideas) that came across your mind when you hear idioms that are embedded in a context when you were taught those new lessons?

Interviewee: yes there are many, yes. This is basically what is going on in everyone's mind.

Interviewer: Did those schemas help you to make sense of idioms? Why?

Interviewee: they did yes.

Interviewer: Some idioms were embedded in historical cultural contexts, others were embedded in religious cultural contexts and some others simulated the environment, which one of these cultural bits was very effective in terms of comprehension and accessibility of idiom's meaning to you?

Interviewee: I cannot remember which bits of culture was easy for me to process but some idioms were easy because I knew them before.

Interviewer: Did you feel the necessity to elaborate a little bit on the cultural context used in those idioms or was it clear for you? Why?

Interviewee:

Interviewer: Why do you think using home culture may or may not help in better comprehension of idioms than target culture??

Interviewee: I do not think so. I think I do not use L1 when learning idioms at all.

Interviewer: Some teachers claim that we need to move forward from target culture teaching based-practice and we need to balance that with home culture teaching based-practice? What do you think?

Interviewee: yes sometimes we need that to facilitate the learning process because home culture helps you to remember and understand in the same time.

\section{Appendix 9: Leyla interview}

Interviewer: How did you find the new lessons so far, (i.e. useful, not really beneficial ... etc.)?

Interviewee: I think they were interesting. They were not boring.

Interviewer: Did you find difficulty understanding idioms of each lesson? Why?

Interviewee: there are idioms which I could guess the meaning but sometimes I couldn't because they were difficult. I reply on the literal meaning of idioms to understand the meaning.

Interviewer: Do you think these lessons especially bits of idioms might be helpful to other students at your level who are dealing with idioms a lot in class? Why? 
Interviewee: yes they would be helpful to other students at my level.

Interviewer: What do you think of teachers who focus a lot on the target culture in class?

Interviewee: because we are learning their language, we need to know their culture. Just little bit to... if we want for example to travel to English countries so it will help us to communicate with them.

Interviewer: In what context do you think idioms should be embedded in to facilitate the process of learning them?

Interviewee: I think it is the context that is familiar to us because it facilitates to get the meaning quickly and to understand what the idiom means exactly.

Interviewer: What kind of schemas (ideas) that came across your mind when you hear idioms that are embedded in a context when you were taught those new lessons?

Interviewee: yes, I did think of familiar examples.

Interviewer: Did those schemas help you to make sense of idioms? Why?

Interviewee: yes they were very helpful to us to understand idioms.

Interviewer: Some idioms were embedded in historical cultural contexts, others were embedded in religious cultural contexts and some others simulated the environment, which one of these cultural bits was very effective in terms of comprehension and accessibility of idiom's meaning to you?

Interviewee:

Interviewer: Did you feel the necessity to use your L1 when learning idioms? Interviewee: yes sometimes I want to know if there is an expression in my L1 that is equivalent to this or that idiom.

Interviewer: Some teachers claim that we need to move forward from target culture teaching based-practice and we need to balance that with home culture teaching based-practice? What do you think?

Interviewee: even if we study English we do not have to forget our culture. There is always something in their culture that we do not accept it so I do not think we should focus on target culture a lot.

\section{Appendix 10: Ahmed interview}

Interviewer: How did you find the new lessons so far, (i.e. useful, not really beneficial ... etc.)?

Interviewee: I think they are the most interesting lessons I have had. We have studied idioms before but not this way. What I found interesting about those lessons is examples that were familiar with our culture and helpful for understanding idioms. Idioms are not something to teach but something to practice. I think we need some cultural environment to teach them.

Interviewer: What do you think of teachers who focus a lot on the target culture in class? 
Interviewee: we need to know about target culture but we need first to .... We need to understand the meaning and then we can put it in its original context. There are some taboos but nowadays nothing is a taboo.

Interviewer: In what context do you think idioms should be embedded in to facilitate the process of learning them?

Interviewee: familiar context to our culture because it is something new to me. First we have to understand the meaning through using familiar context. Interviewer: What kind of schemas (ideas) that came across your mind when you hear idioms that are embedded in a context when you were taught those new lessons?

Interviewee: yes they came to my mind directly. I think about something else, something quite related to religion about the two lives and life after death and if you do something good you get both lives and if you do something bad .... Interviewer: Some idioms were embedded in historical cultural contexts, others were embedded in religious cultural contexts and some others simulated the environment, which one of these cultural bits was very effective in terms of comprehension and accessibility of idiom's meaning to you?

Interviewee: not sure about which parts of culture was easy for me but there were some idioms that were easy to understand.

Interviewer: do you think home culture is helpful in learning idioms?

Interviewee: of course because we are not support to learn words we are supposed to learn the meaning and then we have to use it and....

Interviewer: Some teachers claim that we need to move forward from target culture teaching based-practice and we need to balance that with home culture teaching based-practice? What do you think?

Interviewee: we need to have a strategy. We let the learners understand the meaning through our culture then we can practice or far with this idiom or this lesson into other cultures. 